JCC

9,2

92

\section{Performance monitoring by managerial teams}

Pierre Jinghong Liang

Tepper School of Business, Carnegie Mellon University, Pittsburgh, Pennsylvania, USA and Chinese Academy of Financial Research, Shanghai Jiaotong University, Shanghai, China Madhav Rajan

Stanford University, Stanford, California, USA, and Korok Ray Texas A and M University, College Station, Texas, USA

\begin{abstract}
Purpose - This paper aims to explore the design of management teams when the critical task facing individual managers is monitoring the performance of worker teams and producing performance measures under uncertain information environments.

Design/methodology/approach - The authors use a multi-agent LEN framework - linear contract, exponential utility and normal density - to model the incentive provision and organizational design.

Findings - The main lesson is that the use of performance measures under uncertainty is greatly affected by the potential for free-riding in the very monitoring activities which generate the measures to begin with. Accordingly, the value of having a management team, that is the incremental benefit of having a second manager, depends on the monitoring technology. Of particular importance are the potential free-riding in monitoring effort among multiple managers and synergies gained from having more than one manager, such as correlation among the performance measures produced or improvement due to splitting workers pool into separate groups for each manager to monitor separately.

Originality/value - The paper pushes this line of research further by explicitly modeling the endogenous process of signal generation within a rich economic environment. In this environment, number of workers being evaluated and number of managers who produce the signals are both endogenous. Furthermore, both workers and managers are subject to moral hazard problem. In particular, the managers suffer from potential free-riding problems but may benefit from synergistic forces due to team monitoring.
\end{abstract}

Keywords Organization design, LEN models, Management teams, Performance measurement Paper type Research paper

(C) Pierre Jinghong Liang, Madhav Rajan and Korok Ray. Published in Journal of Centrum Cathedra: The Business and Economics Research Journal. Published by Emerald Group Publishing Limited. This article is published under the Creative Commons Attribution (CC BY 4.0) licence. Anyone may reproduce, distribute, translate and create derivative works of this article (for both commercial \& non-commercial purposes), subject to full attribution to the original publication and authors. The full terms of this licence may be seen at http://creativecommons.org/licenses/by/4.0/legalcode

The authors dedicate the paper to the late Professor Yuji Ijiri of Carnegie Mellon University. Pierre Jinghong Liang gratefully acknowledges the Dean's Summer Research funding of the Tepper School, Madhav Rajan acknowledges the generous support of the Coulter Family Faculty Fellowship at Stanford GSB and Korok Ray acknowledges Texas A\&M University for providing generous financial support. The authors thank Professor Rajiv Banker and an anonymous referee for insightful comments. This article is part of a special issue Guest Edited by Rajiv D. Banker and Vincent Charles.
Journal of Centrum Cathedra: The Business and Economic Research Journal Vol. 9 No. 2, 2016 pp. $92-119$

Emerald Group Publishing Limited 1851-6599

DOI 10.1108/JCC-09-2016-0011 


\section{Introduction}

This paper explores the design of management teams when the critical task facing individual managers is monitoring the performance of worker teams and producing performance measures under uncertain information environments. As a whole, this paper offers a theory of management team based on the idea that organizations optimally balance the management team size, worker team size and pay-forperformance intensity in compensation contracts for management and workers.

Performance measurement has a long-lasting standing in management science and in the history of accounting thoughts in particular. The idea of measuring delivered performance is clearly present in the classic work by Paton and Littleton and is viewed as the central function of business accounting practices. This work is followed by Yuji Ijiri who focuses on accounting measurement in his early work in 1966 and later updated work in Ijiri (1975). The further development of performance measurement is evident in his accountability framework in 1984.

Uncertainty becomes a central presence in accounting thoughts starting in the 1970s. Demski and Feltham (1976) summarized the decision-making under uncertainty framework in accounting research. The explicit combination of performance measurement with uncertainty environment became the forefront of rigorous accounting research starting in early 1980s. Beginning with basic models developed by Holmström (1979) (in a bilateral setting) and Holmström (1982) (in a team setting), the work by Baiman and Demski (1980) open numerous avenues for deeper inquiries into various facets of performance measurement and evaluation under uncertainty. Among these avenues, Banker and Datar (1989) set the standard in research on the statistical properties of signals and (linear) aggregation of performance measures used to evaluate employees.

Our paper pushes this line of research further by explicitly modeling the endogenous process of signal generation within a rich economic environment. In our environment, number of workers being evaluated and number of managers who produce the signals are both endogenous. Furthermore, both workers and managers are subject to moral hazard problem. In particular, the managers suffer from potential free-riding problems but may benefit from synergistic forces due to team monitoring.

Existing and close work includes Huddart and Liang (2003 and 2005), who also examine a team setting but focus on partnership where all profits from production are shared among all partners; thus, shirking incentive can be strong when the number of partners are large. Our paper is different due to the existence of a risk-neutral principal who stands ready to share risk from the production and performance measurement uncertainty. Further, in their paper, monitoring and producing are performed by the same agent (i.e. partners), while agents are specialized in our model (i.e. workers and managers are distinct in our paper).

Within a bilateral employment setting, Liang and Nan (2014) also model endogenous performance measures in an agency setting where the precision of the managerial performance measure may be improved by the managerial reporting effort. The key issue is that this reporting effort is limited by managerial attention because performing one task may have an adverse effect on the cost efficiency of performing another. While we share the modeling feature of endogenous performance measures, management team is not the issue in their paper. 

setup, except their analysis focus on the optimal worker-team size under a single manager. They choose to study a host of issues within the single-manager setting including the weak relation between incentive and risk, optimal worker-team size and potential matching of worker and manager abilities. However, the economic trade-off involving management teams is absent.

We use a multi-agent LEN framework - linear contract, exponential utility and normal density - which is widely used in applied economic models. The framework is introduced by Holmstrom and Milgrom (1987). Feltham and Xie (1994) is among notable papers popularizing the use of LEN in accounting literature. Within the team's setting, McLaughlin (1994), Adams (2006), Hughes et al. (2005) and Autrey (2005) use the same LEN framework as ours, in addition to those we mentioned above.

Specifically, our model follows the main setup as Liang et al.'s (2008) with a major departure of introducing the possibility of multiple managers. The analysis will broadly proceed in two parts. In the first part of the paper, we examine an arbitrary number of managers under a particular joint-production monitoring technology. This provides a general intuition for how the management problem changes as the number of managers change. In the second part, a two-manager setting is considered, and we solve the model under varying monitoring technologies. This is designed to provide a deeper intuition on how the managers interact with their workers and when the management by teams is profitable and when it is not.

The analysis within our multiple-manager framework produces a number of new results. The main lesson is that the use of performance measures under uncertainty is greatly affected by the potential for free-riding in the very monitoring activities which generate the measures to begin with. Accordingly, the value of having a management team, that is the incremental benefit of having a second manager, depends on the monitoring technology. Of particular importance are the potential free-riding in monitoring effort among multiple managers and synergies gained from having more than one manager, such as correlation among the performance measures produced or improvement due to splitting workers pool into separate groups for each manager to monitor separately.

The rest of the paper proceeds as follows. Section 2 lays out the basic framework for the subsequent model analysis. In particular, we consider a joint-monitoring technology and identify the central free-riding disadvantage of designing management teams. In Section 3, we consider the two alternate monitoring technologies and isolate the monitoring synergies that must be present for organizational design to include a team of managers (as opposed to a single manager). We conclude the paper in Section 4.

\section{The basic model}

The model consists of a single risk neutral principal (the firm) contracting with $n$ workers and $L$ managers. Each agent (either a worker or a manager) is effort and risk averse, and the firm contracts with these agents to induce effort. The game proceeds in distinct phases: organizational design and production. Within each phase, there are several stages. Figure 1 outlines the timeline of the game which we now discuss in detail. 
In Stage 1, the firm chooses the number of managers, $L$. In Stage 2, the firm chooses the number of workers, $n$. Finally in Stage 3 , the firm draws its contracts $w_{i}$ for each worker $\omega_{j}$ for each manager. Thus, in the organizational design phase, the firm not only selects the contract parameters but also selects the size and scope of the firm through the number of workers and managers. This sets the broad parameters for the rest of the game.

The next phase is production. Here, both workers and managers exert costly effort to produce output. Workers will select effort $e_{i}$ and managers will select monitoring effort $m_{j}$ according to the contract parameters that the firm selected earlier. Once all agents exert their effort, nature resolves production uncertainty $\varepsilon$, and this realizes output $y$. Finally, managers and workers receive wages based on their output $y$ and their contracts negotiated in advance. The firm then collects profits from the output and the game is complete.

Figure 1 shows the general timeline of the game, and we now turn to the individual stages to define the actions within each stage. This will make explicit the precise activities of each manager and agent. Because the game proceeds sequentially, it is necessary to solve the game backwards. Thus, we first solve for the production phase, taking the organization design as given. Finally, we solve for the organizational design phase at the beginning of the game.

\subsection{The production phase}

Consider the production phase, where workers and managers exert effort, nature resolves production uncertainty $\varepsilon$ and all parties collect their payoffs. This is the last phase of the game, so the agents take the organizational design phase as given. Thus, we treat the number of managers $L$, the number of workers $n$ and the contract parameters as exogenous. This phase will establish the incentive constraints of each of the agents, which reveal their behavior, given the contract parameters which they take as fixed.

The structure of the problem consists of a team of $L$ managers overseeing a group of $n$ workers. The workers exert effort to produce output, and the managers collectively monitor the group of workers. Thus, the managers serve a monitoring function in this phase.

Each worker exerts effort $e_{i}$ at cost of effort $C_{i}\left(e_{i}\right)=0.5 c_{i} e_{i}^{2}$. The cost of effort parameter $c_{i}$ measures the quality/ability of the worker: higher-quality workers have a lower $c_{i}$. Let $N=\{1,2, \ldots, n\}$ denote the set of workers. Joint output is given by:

$$
x=\sum_{i \in N} e_{i}+\varepsilon_{x}
$$

\begin{tabular}{|c|c|c|c|c|c|}
\hline Stage 1 & Stage 2 & Stage 3 & Stage 4 & Stage 5 & Stage 6 \\
\hline $\begin{array}{l}\text { Firm chooses } \\
\text { number of } \\
\text { managers } L \text {. }\end{array}$ & $\begin{array}{l}\text { Firm chooses } \\
\text { number of } \\
\text { workers } n \text {. }\end{array}$ & $\begin{array}{l}\text { Firm draws } \\
\text { contracts } w_{i} \\
\text { and } \omega_{j} .\end{array}$ & $\begin{array}{l}\text { Workers } \\
\text { select } e_{i} \text { and } \\
\text { managers } \\
\text { select } m_{j} \text {. }\end{array}$ & $\begin{array}{l}\text { Nature } \\
\text { draws } \epsilon, \\
\text { yielding } \\
\text { output } y \text {. }\end{array}$ & $\begin{array}{l}\text { Agents } \\
\text { receive } \\
\text { wages, and } \\
\text { firm collects } \\
\text { profits. }\end{array}$ \\
\hline
\end{tabular}

Monitoring by managerial teams

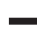

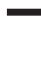


We assume that $x$ is either unverifiable or is realized too late to be used in contracting. Instead, the managers monitor the workers. Each manager is an effort- and risk-averse economic agent who can produce a signal about the collective efforts of the team under his supervision. In particular, each manager $j \in\{1 \ldots L\}$ exerts monitoring effort $m_{j}$ at personal cost $C\left(m_{j}\right)=k_{j} m_{j}$, where $k_{j}$ is the manager's cost of effort parameter. This parameter measures the manager's quality/ability: higher-quality (or lower cost) managers have a lower $k_{j}$. The manager's effort reduces the variance on the team performance measure. Assume $y$ is the only variable on which contracts can be written. We specify that:

$$
y=\sum_{i=1}^{n} e_{i}+\epsilon \text { where } \epsilon \sim N\left(0, \frac{G(n) \sigma^{2}}{\sum_{j} m_{j}}\right)
$$

Note that $\sigma$ measures the uncertainty in performance measurement. We normalize $G(0)$ equal to 0 and assume that $G(n)$ is increasing and strictly convex in $n$, so that measurement becomes noisier as the team size grows. This reflects a basic assumption on the monitoring technology, namely, that the performance of larger teams is harder to measure because of problems with coordination, communication difficulties, etc. In addition, we assume that $G(\cdot)$ satisfies the following technical condition:[1]

$$
\frac{d}{d n}\left(\frac{n\left[G^{\prime}(n)\right]}{G(n)}\right) \geq 0 .
$$

2.1.1 Workers and managers' problems. Task specialization is such that the manager's effort reduces the variance of $y$, while the worker's effort increases its mean. The firm offers a linear contract to each worker, so each worker receives a wage $w_{i}=a_{i}+b_{i} y$. All $n$ workers are equally risk averse with exponential utility and a common coefficient of risk aversion parameter $r$. Thus, workers' preferences assume a meanvariance representation. In certainty equivalent terms, each worker receives $\mathrm{E} w_{i}-$ $r / 2 \operatorname{Var}\left(w_{i}\right)-C_{i}\left(e_{i}\right)$ : expected wages less a risk premium less the cost of effort. Each worker solves:

$$
\max _{e_{i}} a_{i}+b_{i} \mathrm{E} y-\frac{r}{2} b_{i}^{2} \frac{G(n) \sigma^{2}}{\sum^{m_{j}}}-C_{i}\left(e_{i}\right)
$$

yielding the standard incentive constraint, $e_{i}=b_{i} / c_{i}$. Suppose all workers have outside options, denoted by $\bar{u}$, which is normalized to zero[2].

Like the workers, each manager is risk averse with exponential utility and a common coefficient of risk aversion parameter $r$. We assume that the managers and the workers have the same coefficient of risk aversion; this is without loss of generality, as the principal's objective function is separable in the two risk premiums. The firm will set the salaries $\left(a_{i}\right)$ such that each worker's individual rationality constraint binds, given that all other workers select their equilibrium effort levels.

Assume that $m_{j}$ is unobservable so each manager must be motivated to supply monitoring efforts. As with the workers, the firm contracts with the managers in the organizational design phase, a contract which the manager takes as given. In the 
organizational design phase, the firm offers a linear contract to each manager consisting of a salary and a bonus on the team performance measure, i.e. $\omega_{j}=\alpha_{j}+\beta_{j} y$ for each manager $j=1 \ldots L$.

Each manager thus solves:

$$
\max _{m_{j}} \alpha_{j}+\beta_{j} E[y]-\frac{r}{2} \beta_{j}{ }_{j} \frac{G(n) \sigma^{2}}{\sum m_{j}}-k_{j} m_{j}
$$

The manager's payoff consists of his expected wages, minus his risk-premium and minus his personal cost of effort. Observe that his risk premium increases in $G(n)$ and decreases in $\Sigma m_{j}$, which is the sum of all managerial efforts. As all other managers exert more effort to monitor the workers, the performance measurement becomes more precise, and the risk premium decreases. The first-order condition yields the incentive constraint for the manager $j$ :

$$
m_{j}=\beta_{j} \sigma \sqrt{\frac{G(n) r}{2 k_{j}}}-\sum_{k \neq j} m_{k}
$$

The manager's problem is concave even when his personal cost $C(m)$ is linear because his personal benefit of monitoring effort is increasing and concave in $m$ [3]. Even though all workers and the manager are under linear contracts, the provision of incentives to exert effort comes through in different ways. The manager's effort does not affect the expectation of his wage $E \omega_{j}$, but such effort does decrease its variance. Given the manager is risk-averse, he has an incentive to reduce the variance by exerting monitoring effect $m$. Notice that it is critical for obtaining our quantitative results that the same contracting variable $y$ is used in both workers' and managers' linear contracts[4].

While the choice of contracting variable for the workers is natural, we believe the assumption of using the same contracting variable for the managers is a simple way to model the compensation arrangement between the principal and the manager that captured the moral hazard tension of monitoring effort provided by the managers. In practice, managers' compensation is, in large part, determined by the performance of the group under their supervision (Bushman et al., 1995). As long as the performance measure $y$ is available for contracting, the tension we study in this paper remains, while the quantitative result may vary. For example, a more comprehensive framework would include a second task for manager beyond monitoring. In practice, managers may exert productive effort to increase aggregation output. This multi-task arrangement is modeled by Liang and Nan (2014). An alternative performance measure for the managers can be a separate signal, $z_{j}$, about the manager's effort $m_{j}$, in which case a linear manager-contract becomes $\omega_{j}=\alpha_{j}+\beta_{j} y+\gamma_{j} z_{j}$. This type of the modeling choice is similar to Ziv (2000), where the firm provides incentives to managers via a signal about managerial effort that is generated by yet another manager or, ultimately, the principal. While Ziv's model potentially allows for the investigation of multi-layer hierarchies, the imposed complexity is daunting and precludes the development of a tractable framework.
Monitoring by managerial teams 
Observe that the manager's effort increases in $\beta, \sigma, G(n)$ and $r$. All of these parameters inflate the risk premium, which gives the risk-averse manager an incentive to work hard to avoid that disutility.

2.1.2 Free-riding in managerial monitoring effort. Observe that the efforts of different managers are substitutes, rather than complements. When all other managers exert more effort, this increases the precision of the performance measurement, thereby reducing the risk premium. In response, manager $j$ can reduce his costly exertion of monitoring. In effect, manager $j$ free-rides on the monitoring efforts of manager $k \neq j$. This free-riding is an essential feature of all team-based production, and in particular, in this setting, where the function of the manager in this phase is to monitor the workers.

It will be useful to pool the managers' incentive constraints in equation (3). Summing equation (3) over every $j$ :

$$
\sum_{j=1}^{L} m_{j}=\sum_{j=1}^{L} \beta_{j} \sigma \sqrt{\frac{G(n) r}{2 k_{j}}}-(L-1) \sum_{j=1}^{L} m_{j}
$$

Collecting terms, this leads to:

$$
\sum_{j=1}^{L} m_{j}=\sum_{j=1}^{L} \beta_{j} \sigma \sqrt{\frac{G(n) r}{2 k_{j}}}
$$

Thus, total managerial monitoring effort is directly proportional to the manager's risk premium. Total monitoring effort $\Sigma m_{j}$ therefore rises in $\sigma, G(n)$ and $r$. These three parameters moderate the effort of each individual manager, and thus the total managerial effort. But observe also that total effort falls in $L$. Thus, as the number of managers increases, the free-riding effect becomes more pronounced, and every manager exerts less effort, thereby dampening total effort $\Sigma m_{j}$. This is somewhat remarkable, given that we would expect that total effort would simply increase as the firm hires more managers. But the incentive constraint for each manager shows the subtle free-riding effect where each manager reduces his own effort when the total amount of all other managerial effort increases. This is exactly why total effort decreases in the number of managers, rather than increases as one might expect absent these incentive effects.

This production phase has established the precise microeconomic relationship between the workers and managers. Workers collectively create output by exerting effort. Managers monitor these workers by exerting effort to reduce the variance on this output. Because the firm contracts with each agent on output, it can provide incentives for workers to work and managers to monitor.

\subsection{Organizational design phase}

We now move to the organizational design phase to consider the firm's problem of choosing the optimal number of managers and workers, as well as the associated optimal employment contract for each employee.

The organizational design phase consists of three stages. First, the firm chooses the number of managers, then the firm chooses the number of workers and then the firm draws its contracts with the managers and workers. Thus, the firm indeed selects not 
only the nexus of contracts but also the scope of the contracts in terms of the size of the firm. Within the organizational design phase, we work backwards. We first consider the firm's optimal contracts, then the optimal number of workers and finally the optimal number of managers.

When computing its profit function, the firm knows that the production phase follows, and therefore that the agents will react to the firm's contracts. In this sense, the firm is the Stackelberg leader and will substitute the incentive constraints for the manger and worker into its profit function.

2.2.1 Optimal contacts. Assume each unit of output $(x)$ is sold in a competitive market at an exogenous price $q$. The firm maximizes the expectation of revenues less wage payments and substitutes the binding (IR) constraints into its optimization. The firm sets the salary levels $\left(a_{i}, \alpha_{j}\right)$ such that the individual rationality constraint binds for every worker and the manager. Assume the opportunity wage for the workers and the managers is $\bar{u}_{M}$, which is also normalized to zero. The firm therefore maximizes total surplus:

$$
\max _{b_{i} \beta_{j}} \sum_{i=1}^{n}\left[q e_{i}-\frac{c_{i}}{2} e_{i}^{2}-\frac{r}{2} b_{i}^{2} \frac{G(n) \sigma^{2}}{\sum m_{j}}\right]-\sum_{j} k_{j} m_{j}-\frac{r}{2} \sum \beta_{j}^{2} \frac{G(n) \sigma^{2}}{\sum m_{j}}
$$

The firm's profit function can be broken into two pieces, coming from the workers and managers separately. The first piece lies in the brackets above, which contains the output from the team of workers, minus their cost of effort and minus their risk premium. The firm collects output from their effort through the binding participation constraint, so the firm effectively bears the workers' cost of effort and their risk premium. Observe immediately that the expression in brackets contains the tradeoff on worker incentives $b_{i}$ : stronger incentives create more output, but they cause workers to exert more effort (which is costly for them) and also load risk onto workers (which they dislike because of their risk-aversion).

The second piece of the firm's objective function lies in the remaining two terms in expression (4). The first term is the cost of effort for the managers, and the second is the risk premium for the managers. Because the managers do not exert any direct effort on production, increasing managerial incentives $\beta_{j}$ will not affect worker output, but will affect managerial effort $m_{j}$ through the risk premium, evident in the manager's incentive constraint in equation (3). Thus, by raising managerial incentives, $\beta_{j}$, the firm increases the last expression above, but this is offset by each manager endogenously increasing effort $m_{j}$.

The most important terms in the firm's objective function that will govern the choice of incentives are the two risk premium terms, one for the workers and one of the managers. Because of the binding (IR) constraints, the firm holds all agents to their reservation utility, thereby internalizing not only the agent's cost of effort but also his risk premium. Each agent's risk premium is an increasing function of his level of risk aversion, the output uncertainty $\sigma^{2}$, the noise from monitoring larger teams $G(n)$ and his bonus coefficient (either $b_{i}$ for the worker or $\beta_{j}$ for the manager). Naturally, increasing any of these parameters will inflate the variance of output and thereby load more disutility on the agent, hence causing the agent to require a larger compensating differential for bearing risk.
Monitoring by managerial teams 
JCC

9,2

100

Moreover, observe that any increase in total managerial effort will shrink the risk premium because managers by construction reduce variance in output by exerting costly monitoring effort. While the desire to induce production from the worker and monitoring effort from the manager will influence the firm's incentive choice, so will any term that affects the risk premium. In particular, the separability of the firm's objective function in equation (3) shows that many parameters affect the risk premia, but not the cost of effort or production, such as output uncertainty $\sigma^{2}$, complexity of monitoring $G(n)$ or managerial team size $L$.

The first-order conditions yield the optimal incentives for the worker:

$$
b_{i}=q\left(1+\frac{r c_{i} G(n) \sigma^{2}}{\sum_{j} m_{j}}\right)^{-1}=q\left(1+\frac{c_{i} \sigma \sqrt{G(n) r}}{\sum_{j} \beta_{j} / \sqrt{2 k_{j} L}}\right)^{-1}
$$

This gives the optimal worker incentives, taking the managerial incentives $\beta_{j}$ as fixed. Observe immediately that increasing managerial incentives $\beta_{j}$ will allow the firm to increase worker incentives $b_{i}$. This occurs because stronger managerial incentives cause managerial monitoring effort to increase, which decreases the risk premium for both managers and workers, thereby allowing the firm to increase incentives. The risk premium is effectively the cost of incentives, as incentives load risk onto agents and the risk premium captures their compensating differential for bearing that risk. As such, when the risk premium decreases, so does the cost of incentives, and so the firm can thus increase incentives to extract more effort and thus more production out of the worker. In effect, the decrease in risk premium gives the firm freedom to extract more effort out of the worker. Not surprisingly, an increase in risk aversion $(r)$, cost of effort $\left(c_{i}\right)$ or noise $\left(\sigma^{2}\right)$ causes the firm to cut the worker's incentives, delivering the standard trade-off. What is different now is that the manager's effort $\left(m_{j}\right)$ matters in choosing optimal incentives for workers. Of course, the firm affects $m_{j}$ by choosing the manager's incentive $\beta_{j}$ carefully.

A novel and important comparative static is the effect on managerial team size on worker incentives. The key intuition stems from free-riding and the risk premium. Observe from the manager's incentive constraint that total managerial effort decreases as the number of managers increases. This occurs because even though the greater number of managers pulls total managerial effort upward, the free-riding effect leads each manager shade his effort down, thus exerting a countervailing downward pressure on total managerial effort. The second effect swamps the first, so total managerial effort in fact decreases as the number of managers increases. As the risk premium for both the worker and the manager is an inverse function of total managerial effort, both risk premiums increase as the number of managers increases. Of course, these larger risk premiums are costly for risk averse agents, and the firm seeks to minimize this cost by cutting back on incentives. This is why worker incentives decrease as the number of managers increases.

To solve for the optimal incentives, $\beta_{j}$, first substitute each agent's incentive constraint for effort into the firm's profit function: 


$$
\begin{aligned}
\sum_{i=1}^{n}\left[\frac{q b_{i}}{c_{i}}-\frac{b_{i}^{2}}{2 c_{i}}-\frac{r}{2} b_{i}^{2} \frac{G(n) \sigma^{2}}{\left.\frac{\sum \beta_{j}}{L} \sigma \sqrt{\frac{G(n) r}{2 k}}\right]}\right. \\
\quad-k \frac{\sum \beta_{j}}{L} \sigma \sqrt{\frac{G(n) r}{2 k}-\frac{r}{2} \sum_{j} \beta_{j}^{2} \frac{G(n) \sigma^{2}}{\frac{\sum \beta_{j}}{L} \sigma \sqrt{\frac{G(n) r}{2 k}}}}
\end{aligned}
$$

Collecting terms and rearranging, this becomes:

$$
\begin{aligned}
\sum_{i=1}^{n}\left[\frac{q b_{i}}{c_{i}}-\frac{b_{i}^{2}}{2 c_{i}}\right] & -\sum_{i} b_{i} \frac{L \sigma \sqrt{G(n) r k / 2}}{\sum \beta_{j}}-\sum \beta_{j} \frac{\sigma \sqrt{G(n) r k / 2}}{L} \\
& -\sum_{j} \beta_{j}{ }_{j} \frac{L \sigma \sqrt{G(n) r k / 2}}{\sum \beta_{j}}
\end{aligned}
$$

Optimizing the firm's objective function with respect to $\beta_{j}$ results in a first-order condition, from which we can see the principal's tradeoff in choosing the manager's incentive:

$$
\left(\sum b_{i}^{2}+\sum \beta_{j}^{2}\right) /\left(\sum \beta_{j}\right)^{2}-1 / L^{2}-2 \beta_{j} / \sum \beta_{j}=0
$$

Providing more managerial incentive (i.e. increasing $\beta_{j}$ ) induces more managerial effort [equation (3)]. The benefit is twofold. First, it reduces the variance of the performance measure $y$ and (thus) the risk-premium needed for the manager because the manager's contract is written on $y$. Second, increasing $\beta_{j}$ also reduces the needed risk-premium of all workers because the worker contracts are also written on $y$. Notice here that the firm exploits a spill-over effect from the managerial monitoring effort. The manager is self-interested and desires to exert effort to reduce the variation in his own compensation. But in doing so, he reduces the wage variances of all workers (e.g. a spill-over effect). This is beneficial to the firm because it reduces salary costs $\left(a_{i}^{*}\right.$ and $\left.\alpha^{*}\right)$. These two (marginal) benefits are shown as the two positive terms in equation (6). The cost of providing managerial incentives is also twofold. First, a higher incentive leads to more personally costly managerial effort, for which the manager requires compensation. Second, a higher incentive leads to a managerial pay more sensitive to the signal variations, which increases the risk-premium. These two (marginal) costs are shown as the two negative terms in equation (6)[5].

Substituting in the worker's incentive constraint, rearranging terms and examining the symmetric equilibria with $\beta_{j}=\beta$ for each $j$ and $b_{i}=b$ for each $i$ yields the following FOC for $\beta_{j}$ :

$$
\frac{n b^{2}+L \beta^{2}}{L^{2} \beta^{2}}-1 / L^{2}-\frac{2 \beta}{L \beta}=0
$$


JCC

9,2

Rearranging terms, this becomes:

$$
n b^{2}+L \beta^{2}=(1+2 L) \beta^{2}
$$

Solving for the optimal incentive $\beta^{*}$ gives:

$$
\beta^{*}=b^{*} \sqrt{\frac{n}{1+L}}
$$

The manager's incentives $\beta^{*}$ thus increase with each worker's incentives $b^{*}$. Intuitively, as the firm increases $b_{i}$, it induces more effort from the workers and increases the risk premium. To compensate, the firm increases $\beta$ which induces each manager to spend more effort monitoring the workers; in turn, this reduces the risk premium for everyone.

The optimal incentive $\beta^{*}$ posits a relationship between incentives for the manager and the exogenous size of the managerial and worker teams. In particular, $n$ and $L$ have inverse effects on $\beta^{*}$. As the team of workers increases, this increases the risk premium through $G(n)$, as larger teams of workers make monitoring more difficult. In response to this increase in risk premium, the firm seeks to induce more monitoring and increases the incentives for each manager to monitor. Thus, managerial incentives increase when the size of the worker team grows.

At the same time, the firm reduces managerial incentives when the number of managers increases. This occurs for the same reason that the firm reduces worker incentives when $L$ increases. More managers decrease total managerial effort because of free-riding, and this inflates the risk premium for both managers and workers. The firm compensates for this larger risk premia by reducing incentives. This is apparent from the firm's optimization problem. The binding individual rationality constraints force the firm to bear the cost of the risk premia for both the workers and the managers, and these risk premia vary inversely with total managerial effort.

Ultimately, the number of managers $L$ and the strength of the managerial incentives $\beta^{*}$ are substitutes. With many managers, the firm can afford to provide fewer incentives to each; with fewer managers, the firm must provide strong incentives to each.

Combining the previous expressions for $b, \beta$ and the manager's incentive constraint yields the following expression for $b^{*}$ as an implicit function of the model parameters:

$$
b^{*}=q\left(1+\frac{\sigma c \sqrt{G(n) r 2 k}}{\beta^{*}}\right)^{-1}=q\left(1+\frac{\sigma c \sqrt{G(n) r 2 k}}{b \sqrt{\frac{n}{1+L}}}\right)^{-1}
$$

Collecting terms and simplifying, we arrive at expressions for the optimal incentives for the worker and the manager:

Proposition 1. The optimal incentives for the worker and manager are:

$$
\begin{aligned}
b^{*} & =q-\sigma c \sqrt{2(1+L) r k G(n) / n} \\
\beta^{*} & =b^{*} \sqrt{\frac{n}{1+L}}
\end{aligned}
$$


Proofs of all propositions can be found in the Appendix. Thus, managerial team size and agent incentives are substitutes. When the number of managers is large, the firm reduces incentives for both workers and managers. Conversely, when the number of managers is small, the firm increases incentives for both managers and workers. This all happens because large managerial teams induce free-riding among managers, which reduces total managerial effort, thereby increasing the attendant risk premium. The firm selects its incentive package based on the size of this risk premium.

As in the standard model, the optimal worker incentives fall in the worker's cost of effort $c$, the uncertainty $\sigma$ and the worker's risk-aversion $r$. But unlike the standard model, we arrive at a novel comparative static with respect to the size of the management team. Optimal incentives for both the worker and manager decrease as the number of managers increases.

2.2.2 Optimal number of workers. Recall that the equilibrium manager incentive $\left(\beta^{*}\right)$, monitoring effort $\left(m^{*}\right)$ and worker effort $\left(e^{*}\right)$ are all functions of $b^{*}[6]$. From equation (4), we can now write the profit function with a manager for a given $L$ and $n$, denoted by $\Pi(L, n)$, as follows:

$$
\Pi(L, n)=\frac{n\left(b^{*}\right)^{2}}{2 c}, \text { where } b^{*}=q-c \sigma \sqrt{2(L+1) r k G(n) / n}
$$

This is the firm's profit if it draws its contract optimally, assuming both workers and managers respond to this optimal contract according to their incentive constraints. Its profit function takes the size of the firm as given, namely, the number of managers $L$ and the number of workers $n$. To deliver results on optimal firm size, we step back one stage in the organizational design phase where the firm selects the number of workers. For the moment, we take the number of managers $L$ as fixed, which we will relax in the next subsection. Now, we characterize the optimal $n$ in this setting:

Proposition 2. Assume $c_{i}=c$ for all $i \in N$, and $G(n)=n^{\gamma}$. There exists a unique optimal worker-team size, $n^{*}$ :

$$
n^{*}=\left(\frac{q}{\gamma c \sigma \sqrt{2(L+1) r k}}\right)^{\frac{2}{\gamma-1}}
$$

To get tractable results, we assume that $G(n)$ is a power function. There is a large class of functions that satisfies the assumption in equation (2) outlined in the production phase. Under this assumption, we are (remarkably) able to solve for the optimal number of workers in closed-form. The proof of $P 2$ differentiates the firm's profit function with respect to $n$ and then substitutes in the optimal bonus coefficient $b^{*}$ from $P 1$. This delivers the optimal number of workers, $n^{*}$. This closed-form solution generates some novel comparative statics:

Corollary 1. The optimal worker-team size is decreasing in measurement uncertainty $\sigma$, worker risk aversion $r$, number of managers $L$ and worker and manager costs of effort, $c$ and $k$.

The intuition behind this corollary stems from the combination of two forces: the optimal incentive $b^{*}$ and the risk premium. As any of the exogenous parameters $(\sigma, c, k$ or $r$ ) increase, this inflates the risk premium. As such, this loads risk onto the worker, 
JCC

9,2

104

and the firm compensates by reducing the bonus coefficient $b^{*}$. This is clear from the expression for $b^{*}$ from $P 1$. But the firm now has another instrument to help adjust for this increase in the risk premium, the number of workers. Thus, the firm also reduces the size of the worker team to further compensate for the larger risk premium that arises from increases in the exogenous parameters. This illustrates how the firm will use both instruments, incentives and team size, to adapt to changes in the environment, such as production uncertainty, risk preferences, cost of effort, etc.

This corollary also shows that workers and managers are substitutes rather than complements. This is clear because the optimal number of workers shrinks as the number of managers increases. Why does this happen? As the number of managers $L$ increases, recall from the free-riding effect that total managerial effort decreases, thereby lifting the risk premium. The firm then compensates for this larger risk premium by hiring a fewer number of workers. Thus, the number of workers and the number of managers are inversely related. This is the sense in which the managerial team size and the worker team size are substitutes (If $n^{*}$ increased with $L$, they would be complements).

Substituting the optimal worker team size $n^{*}$ into the optimal incentive coefficient $b^{*}$ for the worker gives:

$$
b^{*}\left(n^{*}\right)=q(\gamma-1) / \gamma
$$

Remarkably, this leads to the following invariance property of the optimal incentive coefficient.

Corollary 2. Evaluated at $n^{*}$, the optimal incentive $b^{*}$ is invariant with respect to measurement uncertainty $\sigma$, worker risk aversion $r$, number of managers $L$ and worker and manager cost of efforts, $c$ and $k$.

This invariance property proves the richness of modeling firm structure in addition to firm contracts. When the firm has multiple instruments at it behest, it can use the size of the worker team to absorb all of the variation in the exogenous parameters of interest $(c, k, \sigma$ and $r)$, while the incentive coefficient $b^{*}$ can remain fixed. This invariance property may explain why variation between incentive plans is small relative to variation between firm size. With multiple instruments, the firm can use team size to adjust to its environment and leave the incentive coefficient unchanged. This invariance property generalizes the result first discovered in Liang et al. (2008).

Substituting this optimal $n^{*}$ into the firm's profit function (for a fixed $L$ ) gives:

$$
\Pi\left(L, n^{*}\right)=\frac{n\left(b^{*}\left(n^{*}\right)\right)^{2}}{2 c}=\frac{n^{*} q^{2}(\gamma-1)^{2}}{2 c \gamma} .
$$

Because the optimal worker team size $n^{*}$ decreases in the number of managers $L$, the expression above shows that the same is true for the firm profit function. Thus:

$$
\frac{\partial \Pi}{\partial L}\left(L, n^{*}\right)<0 .
$$

Ex-post profits are thus decreasing in the number of managers. Indeed, this arises because of the free-riding among managers in the production phase. As the firm increases the number of managers, each manager free rides off of the effort of his peers, 
thus decreasing total managerial effort, thereby inflating the risk premium. The firm responds by decreasing the number of workers, which ultimately decreases revenue and profits. The countervailing force is that more managers lead to better business development, as they are more likely to come up with a new idea. The balance between these two forces will determine the optimal number of managers, to which we now turn.

2.2.3 Optimal number of managers. We now turn to the final stage of the analysis which is the first stage of the game, namely, selecting the optimal number of managers. The firm will choose this optimal number L* assuming that in each stage forward, all agents are acting rationally and responding to their contracts and the organizational structure. Now, it is only necessary to write down the expected profits at stage one.

$\Pi(L)$ is firm profits from production. The firm will thus maximize expected profits and therefore chooses the number of managers to solve.

$$
\max _{L} \Pi(L)
$$

As $\Pi^{\prime}(L)<0$ from equation (7), larger teams of managers induce more free-riding, which dampens managerial effort and erodes firm profits. Having a single manager is the optimal organizational design that would maximize profit[7].

\section{Synergistic monitoring technologies}

The monitoring technology we deployed in the previous section highlights the disadvantages of management team due to free-riding. In this section, we consider monitoring technologies which highlight the synergies typically accrued to team production. Specially, we explore the idea that more managers may catch each others' mistakes (i.e. negative correlation among signals) and the opportunity to specialize by splitting worker groups into smaller sub-groups.

To focus on the role of synergies, we confine our modeling in the case of two managers for the rest of the paper. The key organizational design trade-off is now between a single manager or two managers (as opposed to the optimal number $L^{*}$ managers). Our goal is to analyze the key contribution of expanding the size of the management team to increase worker incentives. Therefore, we focus on the interaction of the monitoring activities between the two managers[8].

Two examples are considered, which highlight the two sources of synergy. First, a monitoring synergy is derived from a natural (negative) statistical correlation between two signals independently produced by the two managers. In the second example, the two managers work jointly to produce two signals, each informative about a subgroup of the worker team. This scenario is analogous to analyzing the optimality of splitting a team into sub-groups. Taken together, our findings in this section yield several implications for the value of using multiple managers, the nature of optimal managerial incentives in such settings and, finally, the optimal design of worker teams.

\subsection{Independent monitoring with correlated signals}

We consider a two-manager setting where each manager works independently to produce a separate, verifiable signal about the performance of the entire worker team. This setting will allow us to more precisely define the interaction between two managers under different specifications of how they actually monitor their team of workers. Later, we will turn to the general case of any number of managers. With two managers, this

\section{Monitoring by managerial teams}

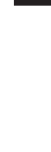


JCC

9,2

results in a total of two contractible signals, denoted by $y_{1}$ and $y_{2}$, respectively. The distribution of performance measures in this scenario can be characterized as follows:

$$
y_{1}=\sum_{i \in N} e_{i}+\epsilon_{1} \text {, and } y_{2}=\sum_{i \in N} e_{i}+\epsilon_{2}
$$

where

$$
\left[\begin{array}{l}
\epsilon_{1} \\
\epsilon_{2}
\end{array}\right] \sim N\left(\left[\begin{array}{l}
0 \\
0
\end{array}\right],\left[\begin{array}{cc}
\frac{G(n) \sigma^{2}}{m_{1}} & \rho G(n) \sigma^{2} \\
\rho G(n) \sigma^{2} & \frac{G(n) \sigma^{2}}{m_{2}}
\end{array}\right]\right) .
$$

The correlation between the two signals captures the idea that the two managers monitor the same worker environment, and, as such, their errors may be correlated. Such correlation may be positive, as when the evaluators are subject to similar shocks in their observations of worker performance, or negative, as when biases or errors may reverse or differ across the two managers' evaluations[9]. In practice, such negative correlation may emerge when firms must choose a second performance measure to be added to an existing one as part of its internal control systems. In this choice problem, one issue is the error-correlation between the first and second measure. This is exactly what Rajan and Sarath (1997) study in single-agent agency setting. In that context, an example of a practical question is:

[...] whether using certain variations of earnings (such as altering the components of net income) can lead to more efficient contracting because of the differential time-series correlations between stock returns and these accounting measure. (p. 150)

With the availability of a second signal, the contracts for the workers are modified because the firm now has additional incentive coefficients at its disposal. In keeping with the LEN framework, we assume that the worker contracts are structured to be linear in the two performance signals. For worker $i \in N$, wages are thus given by:

$$
w_{i}=a_{i}+b_{1 i} y_{1}+b_{2 i} y_{2} .
$$

For manager $j, j=1,2$, we restrict attention to contracts that are linear in the signal produced by the manager's efforts, i.e. each manager's compensation is given by:[10]

$$
\omega_{j}=\alpha_{j}+\beta_{j} y_{j}
$$

Adding a second manager introduces three separate effects to the base model with a single-manager. First, there is a benefit from gaining an additional performance signal of workers, which would improve contracting. This effect strictly increases firm profit. Second, there is an incentive cost of acquiring the signal. This effect changes the endogenous monitoring activities $(m)$ and strictly decreases firm profit. The third effect comes from the ability to adjust team size after acquiring the additional manager. We analyze these three effects in sequence.

3.1.1 Cost and benefit of the second manager. First, we consider a slightly altered setting where the second manager is not subject to moral hazard. Consider this the first 
best benchmark, as we ignore the moral hazard issues that arise with the second manager. As a result, the owner is able to choose the amount of monitoring and simply pays the manager his/her personal cost. We compute firm profit for this setting, denoted by $\Pi_{I I}^{*}(\rho, n)$, and compare the profit with that of the single-manager setting (i.e. $\left.\Pi(n)\right)$ :

Proposition 3. For any fixed firm size $n$ and all $\rho$ :

$$
\Pi_{I I}^{*}(\rho, n)>\Pi(n) \text { and } \frac{\partial}{\partial \rho} \Pi_{I I}^{*}(\rho, n)<0 .
$$

We thus find that the second signal is always beneficial and its value is decreasing in its correlation $(\rho)$ with the first signal. This result is reminiscent of findings in Feltham and Xie (1994) and Christensen and Sabac (2002), where both signals are assumed to be available for free. We next incorporate the incentive cost of acquiring the second signal by motivating a self-interested (second) manager. Therefore, this is the second-best equilibrium, as we consider the moral hazard issue with the manager. For each pair of values $(\rho, n)$, denote the equilibrium profit in the setting where both managers are subject to moral hazard by $\Pi_{I I}(\rho, n)$. We provide a stark characterization of the difference in profits relative to the single-manager setting, as a function of the correlation $(\rho)$ in the managers' signals:

Proposition 4. Assume $c_{i}=c$ for all $i \in N$, and $k_{j}=k$ for all $j=1,2$. For any fixed firm size $n$ :

$$
\begin{array}{ll}
\text { if } \quad \rho>0, & \Pi_{I I}(\rho, n)<\Pi(n) ; \\
\text { if } \quad \rho=0, & \Pi_{I I}(\rho, n)=\Pi(n) ; \\
\text { if } \quad \rho<0, & \Pi_{I I}(\rho, n)>\Pi(n) .
\end{array}
$$

In the proof, we demonstrate an even stronger result - the marginal profit from adding a second manager is monotonically decreasing in the level of correlation. Together, $P 3$ and $P 4$ illustrate the twin effects of hiring a second manager. It is instructive to review the zero-correlation case $(\rho=0)$ as a point of reference. When an additional informative signal $\left(y_{2}\right)$ is available for contracting, it may seem that this would lead the principal to a solution closer to the "first-best". However, hiring a second manager increases the costs to the firm. In addition to the direct costs (i.e. the personal cost of monitoring and the risk-premium due to the second manager), there are indirect costs of imposing the risk of the second signal on each worker whose pay depends on the signal. The principal takes both the direct and indirect costs into account when designing worker and manager contracts. When signals are uncorrelated, the benefit is exactly offset by the costs[11].

Now consider the negative correlation cases. Two additional factors come into play. First, with negative correlation, the overall risk-premium is lowered for any given level of bonus rates. Second, lowered risk lowers the cost of inducing worker effort, so the principal can now increase the incentive rate for the workers to increase production. As a result, negative correlation increases firm profit. Parallel (but opposite) arguments follow in the positive correlation case[12].

As $P 4$ demonstrates, the key to the value of having two managers is the negative correlation between the two signals, which is effectively a form of monitoring synergy. Such negative correlation may be a natural result of different monitoring styles brought 
forth by different managers or may reflect the effect on performance measures of exogenous events that vary randomly as to which manager they affect. Similar to a gain from diversification, the net effect is to reduce the total error (or noise) in the monitoring system.

3.1.2 Optimal team size with a second manager. The third effect of adding another manager is that on team size. In particular, we are interested in comparing the optimal team size in the two-manager setting, which we denote by $n_{I I}^{*}$, to that in the single-manager case, denoted by $n^{*}$. In other words, we wish to understand whether hiring an additional manager who provides yet another evaluative signal on worker performance induces the principal to hire more or fewer workers. Based on the analysis above, it is clear that the answer to this question must depend on the correlation between the two signals:

Proposition 5. Assume $c_{i}=c$ for all $i \in N, k_{j}=k$ for all $j=1,2$. When firm size $n$ is endogenous, the optimal $n_{I I}^{*}$ satisfies:

$$
\begin{aligned}
& \text { if } \rho>0, \quad n_{I I}^{*}<n^{*} ; \\
& \text { if } \rho=0, \quad n_{I I}^{*}=n^{*} ; \\
& \text { if } \rho<0, \quad n_{I I}^{*}>n^{*} .
\end{aligned}
$$

To understand this result, it helps to again consider the zero-correlation case. Recall that for every fixed team size, the profit function with two managers is identical to that with a single manager. It is not surprising then that the optimal team sizes are identical as well. Now consider the case of positive correlation. A positive correlation lowers the incentive for each worker $\left(\partial b_{i} / \partial \rho<0\right)$, leading to lower worker efforts $\left(e_{i}\right)$. Lower worker productivity reduces the marginal benefit of maintaining a larger team. Another effect of the positive correlation is the loss in profit due to the additional risk premium needed to compensate each agent. The marginal effect of increasing $n$ on the loss in profit is thus substantial. Accordingly, in comparison to the single-manager case (or equivalently, the setting with two managers and zero correlation), the optimal team size is smaller.

With negatively correlated signals, the risk premiums for a given bonus rate are lower, bringing in an additional benefit of enlarging the worker team. As before, negative correlation also affects worker incentives. The difference here is the presence of a subtle interaction between the variance effect and the covariance effect on worker efforts $\left(e_{i}\right)$. On one hand, a larger team induces more negative covariance between the two signals, making a higher bonus rate more attractive; on the other hand, a larger team induces higher variances in each signal, making a lower bonus rate more attractive. The overall effect is to drive the optimal team size to be larger than in the single-manager setting.

Finally, we note that the profit comparison across the single-manager and two-manager settings is unaffected by the adjustment of team size to its optimal levels. As in $P 4$, even when team sizes are attuned to be efficient in light of the correlation in performance signals, it is strictly valuable for the owner to employ a second manager when, and only when, the signals he generates are negatively correlated with those of the existing manager. 
To supplement the analysis above, we explore the synergy derived from the team work of the two managers. We use a variant of the "Joint Monitoring" in Section 2. The major difference is that we now specify that the two managers can work together to produce two signals, where each signal is informative about the collective effort of a separate sub-group of workers. We label this "Joint Specialized Monitoring" assignment or simply JSM. The monitoring technology behind the JSM assignment is characterized as follows:

$$
\begin{aligned}
& y_{1}=\sum_{i=1}^{\frac{n}{2}} e_{i}+\epsilon_{1} \quad \text { where } \quad \epsilon_{1} \sim N\left(0, \frac{H(n) \sigma^{2}}{m_{1}+m_{2}}\right) ; \\
& y_{2}=\sum_{i=\frac{n}{2}+1}^{n} e_{i}+\epsilon_{2} \quad \text { where } \quad \epsilon_{2} \sim N\left(0, \frac{H(n) \sigma^{2}}{m_{1}+m_{2}}\right) .
\end{aligned}
$$

Note that each signal is now focused on a sub-group of the worker team that is half in size. The precision of each signal is affected by the monitoring effort by both managers, capturing the idea of joint managerial activities. The benefit of having the managers work jointly is that their interaction allows them to produce signals that are more focused (e.g. have lower variance). This can be achieved when managers communicate with each other and are able to isolate the contribution of each sub-group within the worker team. As a result, each signal is more precise than if the managers had worked independently. Function $H(n)$ captures the synergy generated by asking the two managers to work together to produce specialized signals. If $H(n)=G(n)$, no synergy is present. That is, even though the teams are half the size, the variance of the team performance is the same as before splitting. If $H(n) \leq G(n)$, a synergy is present (e.g. $H(n)=G(n / 2))[13]$. Compared with the joint monitoring in Section 2 where free-riding cost is a dominant cost of adding a manager, the splitting of the worker-team setting introduces a potential benefit of adding a second manager, as it may increase the measurement precision. The key to the success of adding a second manager in this setting thus lies in the tradeoff between the synergy benefit and the shirking incentive inherent in joint monitoring activities.

Using the solution techniques developed earlier, we can solve the principal's problem for the JSM setting. We next show that under the JSM assignment, the profit with two managers exceeds than with a single manager if synergy and the value of output $(q)$ are high enough:

Proposition 6. Assume firm size $\mathrm{n}$ is exogenous, $c_{i}=c$ for all $i \in N$, and $k_{j}=k$ for all $j=1,2$. Let $G(n)=n^{2}$ and $H(n)=G(n / 2)$, if the firm chooses between hiring one manager and hiring two managers with the JSM assignment, the firm will hire two managers if and only if $q$ is large enough.

In deciding whether to expand the number of managers, the usual direct and indirect cost associated with hiring a second manager must be considered, as well as the hidden cost of shirking between the two managers. Notice that with the presence of synergy, each signal is 

case. When such synergy (indexed by the $H(n)$ function) is substantial, hiring a second manager with a JSM assignment overcomes not only the usual direct and indirect cost of the additional monitoring activity but also the hidden cost due to the induced free-riding incentives associated with multiple managers. In that case, the JSM assignment allows the firm higher profits than the single-manager setting.

The analysis of the two-manager setting indicates that the desirability of hiring more managers lies in the synergy/complementarity that exists with group monitoring (such as the low-variance specialized signals in the JSM setup). Given the free-riding and indirect costs associated with the expansion of the size of the management team, it is essential for organizations to realize substantial synergy for group monitoring to be viable[14].

\section{Conclusion}

This paper is intended to open the inquiry into the economics of management teams which are prevalent in management practice. We choose to focus on the monitoring function of the managerial tasks and the model is designed to highlight the trade-offs involved in motivating monitoring incentives. Analysis shows that the scope for free-riding can be very severe theoretically, and synergies must be identified in building managerial teams for the monitoring function.

Future works are suggested to explore additional synergies in monitoring such as dynamic consideration of reputation-building and career concern of the manager as well as the other adjacent tasks to monitoring such as interaction with outside monitors such as analysts and auditors.

\section{Notes}

1. This condition is not too restrictive and is satisfied by a wide range of functional forms. In particular, it holds for all power functions $\left(G(n)=A n^{\gamma}, A>0, \gamma>1\right)$, as well as any general polynomial function with positive coefficients. It is also satisfied by any function in the exponential class $\left(G(n)=A\left(e^{n}-1\right), A>0\right)$. Finally, note that the condition is implied by, and is therefore weaker than, a requirement that $G(n)$ be weakly log-convex.

2. Notice that for each worker, the effort choice is also a dominant strategy response in the workers' subgame.

3. A benefit of linear personal cost is that it provides tractability. Other functional forms of $C(m)$ provide similar economic intuition, but result in mathematical expressions of far greater complexity.

4. Notice the worker effort portion of the contracting variable $y$ has no incentive effects on the manager, thus contracting on an alternate variable $y^{\prime}=y-\sum_{i=1}^{n} e_{i}=\varepsilon$ would induce the identical managerial effort. However, the presence of such a noise-only measure would alter the optimal workers' contracts if they are allowed to be changed as well, as now the Principal can generate a perfect measure of total worker efforts, which would change the demand for a manager to begin with.

5. Consider a slight alteration of the model where the manager exerts a productive effort, say $e_{m}$, which, similar to workers' efforts $e_{i}$, increases the output and the aggregate performance measure $y$. When choosing the optimal $\beta_{j}$, the principal now must consider the marginal benefit and cost of inducing $e_{m}$, in addition to the four effects consider in equation (6). 
However, so long as these additional marginal effects are well-behaved (i.e. smooth and bounded), their only impact is to make the optimal $\beta_{j}$ quantitatively different. The fundamental tradeoff in the managerial monitoring activities persists and leads to the same qualitative results.

Monitoring by managerial teams

6. The maintained assumption here is that $b^{*}>0$. We rule out combinations of parameters such that the above equation gives a negative $b^{*}$ because that implies equilibrium worker incentives would be set to zero, effectively shutting down production.

7. This result, while stark, reflects our modeling choice. We have deliberately ruled out other functions or role for manager. In practice, there may be a sufficient reason to establish a management team. Our result from this section points out an extreme form of its cost: free-riding in monitoring task.

8. We do not intend to analyze the comprehensive interaction between two manager agents, which can be very complex, see extensive literature on relative performance evaluation, possible collusion, etc. More broadly, firms may have reasons to use an additional manager that are unrelated to their monitoring function, such as providing leadership and training employees.

9. Note that the covariance of the signals is independent of either manager's effort. This specification can be recovered from the following, more detailed, construction: for manager $j \in 1,2$, signal $y_{j}$ is the mean of a sample drawn from a distribution of a more primitive signal or data, denoted $z_{j}$. At a personal cost of $k m_{j}$ (or $k$ dollars per draw), the sample size is $m_{j}$. Suppose population $z_{j}$ is normally distributed with a population mean of $\Sigma_{i \in N} e_{i}$, variance $\operatorname{Var}\left(z_{j}\right)=G(n) \sigma^{2}$ and $\operatorname{Cov}\left(z_{1}, z_{2}\right)=\rho G(n) \sigma^{2}$. From here, it is straightforward to show that $y_{j}=\sum_{l=1}^{m_{j}} z_{j l} / m_{j}$ follow the joint distribution specified in the text.

10. We do this for reasons of tractability. More generally, the owner could compensate each manager on the signals generated by both managers. There is no incentive gain to doing so (because the monitoring effort only affects the variance of the manager's own signal); however, a potential second-order benefit arises via better risk-sharing because of the correlation in the signals. It can be shown that each manager would be induced to work harder at monitoring if his contract were based on both signals. The reason is that the improved risk-sharing allows the principal to place a higher weight on the manager's own signal, leading to an increase in induced monitoring activity. Unfortunately, the optimal incentive weights can no longer be derived in closed-form. Nevertheless, as long as the correlation levels are not extreme, $P 4$ continues to hold and sufficient conditions can be generated for $P 5$ to hold as well. Moreover, after extensive numerical analysis, we have not uncovered a single instance in which either result is violated under the more general contracting arrangement. Details are available on request.

11. Further, it is easy to see how monitoring activity by the second manager changes between the two settings. When there is no moral hazard with the second manager (in P3), the principal requests more monitoring from the second manager, which makes the second signal more precise. As a result, the principal places greater incentive weight on the second signal in the workers' contracts. In $P 4$, the principal induces the same monitoring effort from each manager and places identical weights on the two signals in the workers' contracts.

12. Rajan and Sarath (1997) demonstrate the value of negatively correlated signals in a single-agent setting where the signals are available for free (i.e. no direct or indirect incentive costs). Christensen and Sabac (2002) conduct a similar analysis within the LEN framework 
JCC

9,2

and show that having two free signals, regardless of correlation, is always preferred to having just one signal. The key reason is that the marginal effect of increasing one incentive coefficient (such as $b_{1}$ ) on the risk-premium due to the correlation is smaller (in the scale of $\left.(r / 2) b_{2} \rho \sigma_{1} \sigma_{2}\right)$ than that on the risk-premium due to the variance (proportional to $r b_{1} \sigma_{1}^{2}$ ). In addition, their analysis implies that profit is strictly decreasing in the level of correlation.

13. This specification represents substantial synergy, especially when $G($.$) is convex (such as$ $G(n)=n^{2}$ ). A study by Marino and Zabojnik (2004) also considers the optimality of splitting a team into two sub-groups. While we consider the resulting monitoring synergies, their key driving force is the incentive tradeoff of holding a tournament between two groups of risk-neutral workers.

14. In fact, we can show in the JSM setting that if synergy exists but is not large, say $H(n)=$ $G(n) / 2$, while $G(n)=n^{2}$, the JSM assignment is inferior to the single-monitor setting for any value of $q$.

15. To sidestep needless technical complications, we restrict attention throughout to parameter spaces for which the optimal incentive weights are strictly positive and bounded. This is primarily an issue only when correlation levels are extremely negative.

\section{References}

Adams, C.P. (2006), “Optimal team incentives with CES production”, Economics Letters, Vol. 92 No. 1, pp. 143-148.

Autrey, R. (2005), “Team synergy, team composition and performance measures”, Harvard Business School Working Paper.

Baiman, S. and Demski, J.S. (1980), "Economically optimal performance evaluation and control systems", Journal of Accounting Research, Vol. 18, pp. 184-220.

Banker, R.D. and Datar, S.M. (1989), "Sensitivity, precision, and linear aggregation of signals for performance evaluation”, Journal of Accounting Research, Vol. 27 No. 1, pp. 21-39.

Bushman, R., Indjejikian, R. and Smith, A. (1995), "Aggregate performance measures in business unit manager compensation: the role of intrafirm interdependencies", Journal of Accounting Research Vol. 33 No. 3, pp. 101-128.

Christensen, P.O. and Sabac, S. (2002), "Dynamic agency and accounting informativeness", University of Alberta Working Paper, Alberta.

Demski, J.S. and Feltham, G.A. (1976), Cost Determination: A Conceptual Approach, Iowa State Press, Iowa.

Feltham, G. and Xie, J. (1994), "Performance measure congruity and diversity in multi-task principal/agent relations", Accounting Review, Vol. 69 No. 3, pp. 429-453.

Holmström, B. (1979), "Moral hazard and observability”, Bell Journal of Economics, Vol. 10 No. 1, pp. 74-91.

Holmström, B. (1982), "Moral hazard in teams”, Bell Journal of Economics, Vol. 13 No. 2, pp. 324-340.

Holmstrom, B. and Milgrom, P. (1987), "Aggregation and linearity in the provision of intertemporal incentives", Econometrica: Journal of the Econometric Society, Vol. 55 No. 2 , pp. 303-328.

Huddart, S. and Liang, P.J. (2003), “Accounting in partnerships”, The American Economic Review, Vol. 93, pp. 410-414.

Huddart, S. and Liang, P. (2005), "Profit sharing and monitoring in partnerships", Journal of Accounting and Economics, Vol. 40 Nos 1/3, pp. 153-187. 
Hughes, J., Zhang, L. and Xie, J.Z. (2005), "Production externalities, congruity of aggregate signals, and optimal task assignments", Contemporary Accounting Research, Vol. 61 No. 1, pp. 398-408.

Ijiri, Y. (1975), Theory of Accounting Measurement: 10, American Accounting Association, Sarasota.

Monitoring by managerial teams

Liang, P.J. and Nan, L. (2014), "Endogenous precision of performance measures and limited managerial attention”, European Accounting Review, Vol. 23 No. 4, pp. 693-727.

Liang, P., Rajan, M. and Ray, K. (2008), "Optimal team size and monitoring in organizations”, Accounting Review, Vol. 83 No. 1.

Marino, A. and Zabojnik, J. (2004), "Internal competition for corporate resources and incentives in teams”, RAND Journal of Economics, Vol. 35 No. 4, pp. 710-727.

McLaughlin, K. (1994), "Individual compensation and firm performance: the economics of team incentives", University of Chicago - George G. Stigler Center for Study of Economy and State Working Paper, Chicago.

Rajan, M.V. and Sarath, B. (1997), "The value of correlated signals in agencies”, RAND Journal of Economics, Vol. 28, pp. 150-167.

Ziv, A. (2000), "Information technology and optimal firm structure", Journal of Accounting Research, Vol. 38 No. 1, pp. 297-328.

\section{Further reading}

Paton, W. and Littleton, A. (1940), An Introduction to Corporate Accounting Standards, American Accounting Association, Sarasota.

\section{Appendix}

Proof of $\mathrm{P} 2$

Firm profit for given $L$ and $n$ is:

$$
\Pi(L, n)=\frac{n\left(b^{*}\right)^{2}}{2 c} \text { where } b^{*}=q-\sigma c \sqrt{2(L+1) r k G(n) / n}
$$

Suppose $G(n)$ is power function: $G(n)=n^{\gamma}$. Solve for optimal $n$, first-order condition implies:

$$
\frac{\partial}{\partial n} \Pi(L, n)=\frac{1}{2 c}\left[\left(b^{*}\right)^{2}+n 2 b^{*}\left(-\sigma c \sqrt{2(L+1) r k} \frac{(\gamma-1)}{2} n^{\frac{\gamma-3}{2}}\right)\right]
$$

Second-order condition is satisfied if $\gamma>1$. FOC implies:

$$
b^{*}=n \sigma c \sqrt{2(L+1) r k}(\gamma-1) n^{\frac{\gamma-3}{2}} .
$$

Rewriting:

$$
q-\sigma c \sqrt{2(L+1) r k n} n^{\frac{\gamma-3}{2}}=\sigma c \sqrt{2(L+1) r k}(\gamma-1) n^{\frac{\gamma-3}{2}}
$$

Simplifying:

$$
\sigma c \sqrt{2(L+1) r k n}^{\frac{\gamma-3}{2}}=q / \gamma .
$$

Solving for $n^{*}$ : 


$$
n^{*}=\left(\frac{q}{\gamma c \sigma \sqrt{2(L+1) r k}}\right)^{\frac{2}{\gamma-1}}
$$

Thus:

$$
b^{*}\left(n^{*}\right)=q-q / \gamma=q(\gamma-1) / \gamma .
$$

Substituting into the profit function, we have:

$$
\Pi\left(L, n^{*}\right)=\frac{n^{*}\left(b^{*}\left(n^{*}\right)\right)^{2}}{2 c}=\frac{n^{*} q^{2}(\gamma-1)^{2}}{2 c \gamma^{2}} \text { where } n^{*}=\left(\frac{q}{\gamma \sigma c \sqrt{2(L+1) r k}}\right)^{\frac{2}{\gamma-1}} .
$$

Proof of $\mathrm{P} 3$

The worker's problem in the two-manager setting is:

$$
\max _{e_{i}} a_{i}+b_{1 i} \sum_{j} e_{j}+b_{2 i} \sum_{j} e_{j}-\frac{c_{i}}{2} e_{i}^{2}-\frac{r}{2} b_{1 i}^{2} \frac{G(n) \sigma^{2}}{m_{1}}-\frac{r}{2} b_{2 i}^{2} \frac{G(n) \sigma^{2}}{m_{2}}-\frac{r}{2} \rho b_{1 i} b_{2 i} G(n) \sigma^{2},
$$

which leads to a first-order condition on effort, $e_{i}^{*}=b_{1 i}+b_{2 i} / c_{i}$.

The original manager's choice of monitoring effort solves the following problem:

$$
\max _{m_{1}} \alpha_{1}+\beta_{1} \sum_{i}^{n} e_{i}-k_{1} m_{1}-\frac{r}{2} \beta_{1}^{2} \frac{G(n) \sigma^{2}}{m_{1}}
$$

leading to the first-order condition, $m_{1}^{*}=\beta_{1} \sigma \sqrt{G(n) r / 2 k_{1}}$.

With these findings, calculate firm profit and the principal's optimization:

$$
\begin{aligned}
& \max _{\beta_{1}, m_{2}, b_{j i}} \sum_{i=1}^{n}\left[\frac{q\left(b_{1 i}+b_{2 i}\right)}{c_{i}}-\frac{\left(b_{1 i}+b_{2 i}\right)^{2}}{2 c_{i}}-\frac{r}{2} b_{1 i}^{2} \frac{G(n) \sigma^{2}}{m_{1}}-\frac{r}{2} b_{2 i}^{2} \frac{G(n) \sigma^{2}}{m_{2}}-\frac{r}{2} \rho b_{1 i} b_{2 i} G(n) \sigma^{2}\right] \\
& -k_{1} m_{1}-k_{2} m_{2}-\frac{r}{2} \beta_{1}{ }^{2} \frac{G(n) \sigma^{2}}{m_{1}} .
\end{aligned}
$$

Now fix $m_{2}=0$ and $b_{2 i}=0$. The above unconstrained maximization problem becomes the corresponding unconstrained maximization problem for a single manager problem. Therefore, the single-manager solution is feasible in the altered two-manager problem. Examining the first-order conditions reveals that the optimal $m_{2}$ and $b_{2 i}$ are not zero, so we have $\Pi_{I I}^{*}(\rho, n)>\Pi(n)$.

Next, we show that the equilibrium profit decreases in $\rho$. Substituting $m_{1}$ into the profit function, the resulting profit function contains only the optimizers $\left(\beta_{1}, m_{2}, b_{i}\right)$ and exogenous parameters. Notice that $\rho$ only appears once as a negative, linear term. It follows immediately from the Envelope Theorem that the equilibrium profit function is decreasing in $\rho$.

Proof of $\mathrm{P} 4$

The worker's problem in the two-manager setting is given by: 


$$
\max _{e_{i}} a_{i}+b_{1 i} \sum_{j} e_{j}+b_{2 i} \sum_{j} e_{j}-\frac{c_{i}}{2} e_{i}^{2}-\frac{r}{2} b_{1 i}^{2} \frac{G(n) \sigma^{2}}{m_{1}}-\frac{r}{2} b_{2 i}^{2} \frac{G(n) \sigma^{2}}{m_{2}}-\frac{r}{2} \rho b_{1 i} b_{2 i} G(n) \sigma^{2},
$$

Monitoring by managerial teams

which leads to a first-order condition on effort, $e_{i}^{*}=b_{1 i}+b_{2 i} / c_{i}$.

Each manager's choice of monitoring effort solves the following problem:

$$
\max _{m_{j}} \alpha_{j}+\beta_{j} \sum_{i}^{n} e_{i}-k m_{j}-\frac{r}{2} \beta_{j}^{2} \frac{G(n) \sigma^{2}}{m_{j}},
$$

leading to the first-order condition, $m_{j}^{*}=\beta_{j} \sigma \sqrt{G(n) r / 2 k_{j}}$.

With these findings, we can calculate firm profit in the two-manager setting. The principal's optimization problem is:

$$
\begin{aligned}
\max _{\beta, b_{i}} & \sum_{i=1}^{n}\left[\frac{q\left(b_{1 i}+b_{2 i}\right)}{c_{i}}-\frac{\left(b_{1 i}+b_{2 i}\right)^{2}}{2 c_{i}}-\frac{r}{2} b_{1 i}^{2} \frac{G(n) \sigma^{2}}{m_{1}}-\frac{r}{2} b_{2 i}^{2} \frac{G(n) \sigma^{2}}{m_{2}}-\frac{r}{2} \rho b_{1 i} b_{2 i} G(n) \sigma^{2}\right] \\
& -k_{1} m_{1}-k_{2} m_{2}-\frac{r}{2} \beta_{1}^{2} \frac{G(n) \sigma^{2}}{m_{1}}-\frac{r}{2} \beta_{2}^{2} \frac{G(n) \sigma^{2}}{m_{2}} .
\end{aligned}
$$

This leads to the following first-order conditions:

$$
\begin{gathered}
b_{1 i}^{*}=\frac{q-\left(1+\frac{r}{2} \rho c_{i} G(n) \sigma^{2}\right) b_{2 i}^{*}}{1+\frac{r c_{i} G(n) \sigma^{2}}{m_{1}}} \text { and } b_{2 i}^{*}=\frac{q-\left(1+\frac{r}{2} \rho c_{i} G(n) \sigma^{2}\right) b_{1 i}^{*}}{1+\frac{r c_{i} G(n) \sigma^{2}}{m_{2}}} \\
\text { and }\left[\frac{r}{2} \frac{G(n) \sigma^{2}}{\left(m_{j}\right)^{2}} \sum_{i=1}^{n} b_{i}^{2}-2 k_{j}\right] \frac{\partial}{\partial \beta_{j}} m_{j}^{*}\left(\beta_{j}\right)=0 .
\end{gathered}
$$

Substituting $m_{j}$ and $\partial / \partial \beta_{j} m_{j}^{*}\left(\beta_{j}\right)$ into the last condition, we arrive at:

$$
\beta_{j}^{*}=\sqrt{\frac{1}{2} \sum_{i=1}^{n} b_{i}^{2}} .
$$

Now simplifying these conditions with identical workers and managers (i.e. $c_{i} \equiv c$ and $k_{i} \equiv k$ ) implies $b_{i}^{*} \equiv b^{*}, \beta_{j}^{*} \equiv \beta^{*}$ and $m_{j}^{*} \equiv m^{*}$. We use these identities to solve $\beta^{*}$ and $b^{*}[15]$. In equilibrium, we have:

$$
\begin{gathered}
\beta^{*}=b^{*} \sqrt{\frac{n}{2}} \\
m^{*}=b^{*} \sigma \sqrt{\frac{G(n) n r}{4 k}}>1 ;
\end{gathered}
$$




$$
\begin{gathered}
b^{*}=\frac{q-\left(1+\frac{r}{2} \rho c G(n) \sigma^{2}\right) b^{*}}{1+\frac{r c G(n) \sigma^{2}}{m^{*}}}=\frac{q-\left(1+\frac{r}{2} \rho c G(n) \sigma^{2}\right) b^{*}}{1+\frac{2 c \sigma \sqrt{r k G(n) / n}}{b^{*}}} \\
\Rightarrow b^{*}=\frac{q-2 c \sigma \sqrt{r k G(n) / n}}{2+\frac{r}{2} \rho c G(n) \sigma^{2}} .
\end{gathered}
$$

Total profits can then be computed as follows:

$$
\begin{aligned}
& \Pi_{I I}(\rho, n)=n\left[\frac{q 2 b^{*}}{c}-\frac{\left(2 b^{*}\right)^{2}}{2 c}-\frac{r}{2}\left(2 b^{* 2}\right) \frac{G(n) \sigma^{2}}{m^{*}}-\frac{r}{2} \rho b^{* 2} G(n) \sigma^{2}\right]-2 k m^{*} \\
& \quad-\frac{r}{2}\left(2 \beta^{* 2}\right) \frac{G(n) \sigma^{2}}{m^{*}}
\end{aligned}
$$

After extensive simplification, this reduces to:

$$
\Pi_{I I}(\rho, n)=\Pi(n) W(\rho, n), \text { where } W(\rho, n)=\frac{2}{2+\frac{r}{2} \rho c G(n) \sigma^{2}} .
$$

Recall that $\Pi(n)$ is the profit with a single-manager case and is given by:

$$
\Pi(n)=\frac{n}{2 c}(q-2 c \sigma \sqrt{r k G(n) / n})^{2} .
$$

When $\rho=0, W(0, n)=1$, so $\Pi_{I I}(0, n)=\Pi(n)$. Combined with the fact $\partial / \partial \rho W(\rho, n)<0$, we immediately obtain $\Pi_{I I}(\rho>0, n)<\Pi(n)<\Pi_{I I}(\rho<0, n)$.

Proof of $\mathrm{P} 5$

From equation (44), differentiating $\Pi_{I I}(\rho, n)$ with respect to $n$ yields the following derivative:

$$
\Pi_{I I}{ }^{\prime}(\rho, n)=\Pi^{\prime}(n) W(\rho, n)+\Pi(n) W_{n}(\rho, n),
$$

where:

$$
W_{n}(\rho, n)=\frac{-r \rho c G^{\prime}(n) \sigma^{2}}{\left(2+\frac{r}{2} \rho c G(n) \sigma^{2}\right)^{2}}
$$

Note that $\operatorname{sign}\left(W_{n}(\rho, n)\right)=\operatorname{sign}(-\rho)$.

Consider $\rho=0$. Because $W(0, n)=1$ and $W_{n}(0, n)=0$, we have $\Pi_{I I}{ }^{\prime}\left(0, n_{I I}^{*}\right)=\Pi^{\prime}\left(n^{*}\right)=0$, leading to $n_{I I}^{*}=n^{*}$. In this setting, the optimal team size exists and is unique.

Now consider $\rho>0$. We have $W(\rho>0, n)>0, W_{n}(\rho>0, n)<0$ and $\Pi(n)>0$. Moreover, from the proof of Lemma $2, \Pi^{\prime}(n) \leq 0$ for all $n^{*} \leq n<\bar{n}$. This implies that $\Pi_{I I}{ }^{\prime}(\rho>0, n)<0$ for all $n^{*} \leq n<\bar{n}$, i.e. it must be the case that $n_{I I}^{*}<n^{*}$. Notice that the optimal team size exists, but is possibly not unique; however, our result establishes that every team size that is optimal is smaller than the optimum from the single-manager case.

Finally, suppose that $\rho<0$. For negative values of $\rho, W_{n}(\rho<0, n)>0, \Pi(n)>0$ and $W(\rho<0, n)>0$. As before, from the proof of Lemma $2, \Pi^{\prime}(n) \geq 0$ for all $0<n \leq n^{*}$, implying that 
$\Pi_{I I}{ }^{\prime}(\rho<0, n)>0$ for all $0<n \leq n^{*}$. As in the positive correlation setting, multiple optima may exist for team size. But we have shown that when $\rho<0$, every optimal $n_{I I}^{*}>n^{*}$.

Proof of P6

We start with each worker's problem under JSM. If $i \in\{1,2, \ldots n / 2\}$, then we have:

$$
\max _{e_{i}} a_{i}+b_{1 i} \sum_{j=1}^{n / 2} e_{j}-\frac{c_{i}}{2} e_{i}^{2}-\frac{r}{2} b_{1 i}^{2} \frac{H(n) \sigma^{2}}{m_{1}+m_{2}}
$$

leading to the first-order condition $e_{i}^{*}=b_{1 i} / c_{i}$. For $j \in\{n / 2+1, n / 2+2, \ldots n\}$, the analogous condition is $e_{j}^{*}=b_{2 j} / c_{j}$. It is easy to see that each worker's contract should depend only on the signal about his own sub-group of the team, i.e. $b_{2 i}^{*}=0$, for $i \notin\{1,2, \ldots, n / 2\}$ and $b_{1 i}^{*}=0$, for $i \notin$ $\{n / 2+1, n / 2+2, \ldots, n\}$.

The manager's problem is:

$$
\max _{m_{j}} \alpha_{1}+\beta_{11} \sum_{i=1}^{n / 2} e_{i}+\beta_{12} \sum_{i=n / 2+1}^{n} e_{i}-k_{j} m_{j}-\frac{r}{2}\left(\beta_{11}^{2}+\beta_{12}^{2}\right) \frac{H(n) \sigma^{2}}{m_{1}+m_{2}}
$$

leading to the first-order condition $m_{j}^{*}=\sigma \sqrt{\left(\beta_{11}^{2}+\beta_{12}^{2}\right) H(n) r / 2 k_{j}}-m_{l}$, for $l \neq j$.

Substituting these two conditions, along with the usual IR constraints, the principal's problem is now:

$$
\begin{aligned}
\max _{\beta_{j}, b_{i}} & \sum_{i=1}^{n / 2}\left[\frac{q b_{1 i}}{c_{i}}-\frac{b_{1 i}^{2}}{2 c_{i}}-\frac{r}{2} b_{1 i}^{2} \frac{H(n) \sigma^{2}}{m_{1}+m_{2}}\right]+\sum_{j=n / 2+1}^{n}\left[\frac{q b_{2 j}}{c_{j}}-\frac{b_{2 j}^{2}}{2 c_{j}}-\frac{r}{2} b_{2 j}^{2} \frac{H(n) \sigma^{2}}{m_{1}+m_{2}}\right] \\
- & k_{1} m_{1}-k_{2} m_{2}-\frac{r}{2}\left(\beta_{11}^{2}+\beta_{12}^{2}+\beta_{21}^{2}+\beta_{22}^{2}\right) \frac{H(n) \sigma^{2}}{m_{1}+m_{2}}
\end{aligned}
$$

leading to the first-order conditions:

$$
b_{1 i}^{*}=\frac{q}{1+\frac{r c_{i} H(n) \sigma^{2}}{m_{1}+m_{2}}} \text { and } b_{2 j}^{*}=\frac{q}{1+\frac{r c_{j} H(n) \sigma^{2}}{m_{1}+m_{2}}} .
$$

For signal $y_{l}$ and manager $j$, we have:

$$
\begin{gathered}
{\left[\frac{r}{2} \frac{H(n) \sigma^{2}}{\left(m_{1}+m_{2}\right)^{2}}\left(\sum_{i=1}^{n / 2} b_{1 i}^{2}+\sum_{i=n / 2+1}^{n} b_{2 i}^{2}\right)-k+\frac{r}{2} \frac{H(n) \sigma^{2}}{\left(m_{1}+m_{2}\right)^{2}}\left(\beta_{11}^{2}+\beta_{12}^{2}\right.\right.} \\
\left.\left.+\beta_{21}^{2}+\beta_{22}^{2}\right)\right] \frac{\partial}{\partial \beta_{l j}} m_{j}^{*}\left(\beta_{l j}\right)-r \beta_{l j} \frac{H(n) \sigma^{2}}{m_{1}+m_{2}}=0,
\end{gathered}
$$

where manager $j$ 's first-order condition implies: 


$$
\frac{\partial}{\partial \beta_{l j}} m_{j}^{*}\left(\beta_{l j}\right)=\sigma \sqrt{\frac{H(n) r}{2 k_{j}}} \frac{\beta_{l j}}{\sqrt{\beta_{1 j}^{2}+\beta_{2 j}^{2}}} .
$$

Simplifying these conditions with identical workers and managers (i.e. $c_{i} \equiv c$ and $k_{i} \equiv k$ ) implies $b_{1 i}^{*}=b_{2 i}^{*} \equiv b^{*}, \beta_{l j}^{*} \equiv \beta^{*}$ and $m_{j}^{*} \equiv m^{*}$. We use these identities to solve $\beta^{*}$ and $b^{*}$. In equilibrium, we then have:

$$
\begin{gathered}
2 m^{*}=\beta^{*} \sigma \sqrt{\frac{H(n) r}{k}} ; \\
b^{*}\left(\beta^{*}\right)=\frac{q}{1+\frac{r c H(n) \sigma^{2}}{2 m^{*}}}=\frac{q}{1+\frac{c \sigma \sqrt{H(n) k r}}{\beta^{*}}} ;
\end{gathered}
$$

and

$$
\left[\frac{r}{2} \frac{H(n) \sigma^{2}}{4 m^{* 2}} n b^{* 2}-k+\frac{r}{2} \frac{H(n) \sigma^{2}}{4 m^{* 2}} 4 \beta^{* 2}\right] \sigma \sqrt{\frac{H(n) r}{4 k}}-r \beta^{*} \frac{H(n) \sigma^{2}}{2 m^{*}}=0 .
$$

Substituting $m^{*}\left(\beta^{*}\right)=\left(\beta^{*} / 2\right) \sigma \sqrt{H(n) r / k}$, we have:

$$
\begin{gathered}
0=\left[\frac{k}{2 \beta^{* 2}} n b^{* 2}-k+\frac{k}{2 \beta^{* 2}} 4 \beta^{* 2}\right] \sigma \sqrt{\frac{H(n) r}{4 k}}-2 k \sigma \sqrt{\frac{H(n) r}{4 k}} \\
0=\left[\frac{k}{2 \beta^{* 2}} n b^{* 2}-k+2 k-2 k\right] \sigma \sqrt{\frac{H(n) r}{4 k}} \\
0=\frac{n b^{* 2}}{2 \beta^{* 2}}-1 \\
\beta^{*}=b^{*} \sqrt{\frac{n}{2}}
\end{gathered}
$$

We can incorporate this into the $b^{*}\left(\beta^{*}\right)$ expression to obtain:

$$
b^{*}=\frac{q}{1+\frac{c \sigma \sqrt{H(n) k r}}{b^{*} \sqrt{n / 2}}}=\frac{q}{1+\frac{c \sigma \sqrt{2 H(n) k r / n}}{b^{*}}}
$$

or

$$
b^{*}=q-c \sigma \sqrt{2 r k H(n) / n} .
$$

Total profits with exogenous $n$, using $2 m^{*}=\beta^{*} \sigma \sqrt{H(n) r / k}=b^{*} \sigma \sqrt{H(n) n r /(2 k)}$, and $(r / 2) \operatorname{Var}(y)=(r / 2) H(n) \sigma^{2} /\left(2 m^{*}\right)=\sigma \sqrt{2 r k H(n) / n} / 2 b^{*}$, is then given by: 


$$
\begin{aligned}
\Pi_{J S}(n)= & n\left[\frac{q b^{*}}{c}-\frac{b^{* 2}}{2 c}-b^{* 2} \frac{\sigma \sqrt{2 r k H(n) / n}}{2 b^{*}}\right]-k\left(2 m^{*}\right)-4 \beta^{* 2} \frac{\sigma \sqrt{2 r k H(n) / n}}{2 b^{*}} \\
= & \frac{n b^{*}}{2 c}\left[2 q-b^{*}-c \sigma \sqrt{2 r k H(n) / n}\right]-k b^{*} \sigma \sqrt{\frac{H(n) n r}{2 k}} \\
& -4\left(b^{*} \sqrt{\frac{n}{2}}\right)^{2} \frac{\sigma \sqrt{2 r k H(n) / n}}{2 b^{*}} \\
= & \frac{n b^{*}}{2 c}\left[2 q-b^{*}-c \sigma \sqrt{2 r k H(n) / n}\right]-\frac{n b^{*}}{2} \sigma \sqrt{2 r k H(n) / n} \\
& -n b^{*} \sigma \sqrt{2 r k H(n) / n} \\
= & \frac{n b^{*}}{2 c}\left[2 q-b^{*}-c \sigma \sqrt{2 r k H(n) / n}-3 c \sigma \sqrt{2 r k H(n) / n}\right] \\
= & \frac{n b^{*}}{2 c}[q-3 c \sigma \sqrt{2 r k H(n) / n}]
\end{aligned}
$$

To show claim in this Proposition re-express $\Pi_{I M}(n)$ as:

$$
\begin{aligned}
\Pi_{J S}(n) & =\frac{n b^{*}}{2 c}[q-3 c \sigma \sqrt{2 r k H(n) / n}] \\
& =\frac{n}{2 c}[q-c \sigma \sqrt{2 r k H(n) / n}][q-3 c \sigma \sqrt{2 r k H(n) / n}]
\end{aligned}
$$

Recall that with a single monitor, the profit function for exogenous $n$ is given by $\Pi(n)=n /(2 c)$ $(q-2 c \sigma \sqrt{r k G(n) / n})^{2}$. If $G(n)=n^{2}$ and $H(n)=G(n / 2)$, the value of a second manager, letting $\alpha=c \sigma \sqrt{r n k}$, is given by:

$$
\begin{aligned}
\Pi_{J S}(n)-\Pi(n) \\
=\frac{n}{2 c}[q-\sqrt{1 / 2} \alpha][q-\sqrt{9 / 2} \alpha]-\frac{n}{2 c}(q-2 \alpha)^{2} \\
=\frac{n}{2 c}[(q-2 \alpha)+\alpha(2-\sqrt{1 / 2})][(q-2 \alpha)+\alpha(2-\sqrt{9 / 2})] \\
\quad-\frac{n}{2 c}(q-2 \alpha)^{2} \\
=\frac{n \alpha}{2 c}[(4-\sqrt{9 / 2}-\sqrt{1 / 2})(q-2 \alpha)+(2-\sqrt{1 / 2})(2-\sqrt{9 / 2})(\alpha)]
\end{aligned}
$$

which is greater than zero if and only if: $q>5 \alpha / 8-4 \sqrt{2} \approx 2.13 \alpha$

\section{Corresponding author}

Pierre Jinghong Liang can be contacted at: liangj@andrew.cmu.edu

For instructions on how to order reprints of this article, please visit our website:

www.emeraldgrouppublishing.com/licensing/reprints.htm

Or contact us for further details: permissions@emeraldinsight.com 